\title{
Influence of the Plant Growth Regulator on the Accumulation of Heavy Metals in Biomass of Barley Loi N.N.
}

\author{
Russian Institute of Radiology and Agroecology, Obninsk, Russian Federation
}

\begin{abstract}
Reduction of the phytotoxic effect of pollutants and restriction of their receipt in the crop is possible due to the use of biologically active compounds - plant growth regulators (PGRs) in the cultivation of crops. In the laboratory and vegetative experiments, the effect of presowing treatment of barley seeds of Elf grade by the Zircon growth regulator was studied in $g$ It was found that the content of cadmium in the soil, significantly exceeding the level of MPC for sod-podzolic medium loamy soil, led to a significant decrease in the plant height of 21 daily barley plants and leaf area (by 17\% relative to control) irrespective of the experiment variant. Rowing plants with background and elevated concentrations of cadmium in water and soil. The presence of cadmium ions inhibited the development of diseases of 7 diurnal barley seedlings. There was a significant decrease in the development of Helminthosporium sativum P., K. et B. - the degree of lesion decreased by $17.7 \%$ and the disease prevalence in barley seedlings decreased by $9.1 \%$ ( $p<0.05)$. Presowing seed treatment with zircon helps reduce the phytotoxic effect of cadmium with an increased content of this element in the solution for seed germination and in the soil. The use of Zircon leads to a decrease in the accumulation of cadmium in the biomass of barley plants at various stages of ontogeny.
\end{abstract}

Keywords: Plant growth regulator, Heavy metals, Biomass, Barley, Cadmium

\section{INTRODUCTION}

Among heavy metals (TM), cadmium is a priority pollutant and one of the most dangerous ecotoxicants. It exhibits pronounced toxic properties at very low concentrations. Entering the soil and plants, cadmium is included in the food chain and enters the human body together with food, then with blood flow - to the liver, where it binds a complex complex with proteins metallothioneins. Cadmium affects the nervous tissue and kidneys, decalculates bone tissue and has a carcinogenic effect. The toxic effect of cadmium on agricultural crops is expressed, first of all, in the reduction of their yield.

Reduction of the phytotoxic effect of pollutants and restriction of their receipt in the crop is possible due to the use of biologically active compounds - plant growth regulators (PPPs) in the cultivation of crops.

The use of Zircon is due to its ability to increase the adaptive capacity of plants to stress agents, which can be attributed to the high content in the soil of TM. In addition, with the help of the Zircon drug, it is possible to compensate for the deficiency of natural plant growth regulators (phytohormones) arising when grown in unfavorable environmental conditions $[1,2]$.

The purpose of the study was to study the modifying effects of the Zircon drug on the accumulation of heavy metals in barley plants.

\section{MAterial AND MethodS}

The object of the study was spring barley (Hordeum vulgare L.) of Elf (Belorussian selection), which was regionalized in the Kaluga region.

In laboratory experiments, the treated and control barley seeds were incubated in filter paper rolls, which were placed in 1-liter glass beakers with $50 \mathrm{ml}$ of distilled water [3] and incubated in a thermostat at $240{ }^{\circ} \mathrm{C}$. In experimental variants, seed treatment with a plant growth regulator Zircon) According to the flow rates, according to the recommendations [4], were carried out on a laboratory rotary installation of the RVO-64 type. Zircon, R (NNPP, NEST M) is a natural mixture of hydroxycinnamic acids (derived from a medicinal plant) belonging to phenolcarbon compounds.

The irradiation of the seeds was carried out on a laboratory gamma-ray unit "Radiologist" $(60 \mathrm{Co})$ at a dose of 1 and $10 \mathrm{~Gy}$ (radiation dose rate of $8.3 \mathrm{~Gy} / \mathrm{min}$ ). Irradiated seeds were germinated in a 
thermostat at $24{ }^{\circ} \mathrm{C}$. On the 7th day after the experiment, the degree of infection of the seedlings with Helminthosporium sativum and Fusarium sp. Was calculated, the percentage of germination was calculated, the length of the main germinal root and sprout was measured, the wet and dry weight of the plants was determined. Repetition of the experiment is 4-fold Development of root rot agents Helminthosporium sativum and Fusarium sp. Studied on naturally infected seeds [5].

The laying of the vegetative experience was carried out according to the standard method [6]. In the vegetation experiments, sod-podzolic medium loamy soil was used, which had the following agrochemical characteristics: $\mathrm{pH}(\mathrm{KCl}) 6.3 ; \mathrm{Ng} 0.4 \mathrm{mEq} / 100 \mathrm{~g}$; Humus $1.79 \%$, cation exchange capacity $20.4 \mathrm{~g} / \mathrm{kg}$; The content of P2O5 is $67 ; \mathrm{K} 2 \mathrm{O}-15.1 \mathrm{mg} / 100 \mathrm{~g}$ of soil [7, 8]. In the sieved and moistened with distilled water up to $60 \%$ of the total moisture capacity (PV), the soil was thoroughly mixed with NRK (in the form of aqueous solutions of $\mathrm{NH} 4 \mathrm{NO} 3, \mathrm{KCl}$ and $\mathrm{KH} 2 \mathrm{PO} 4$ salts) at doses: N0.2 ; P2O5-0.14 and $\mathrm{K} 2 \mathrm{O}-0.14 \mathrm{~g} / \mathrm{kg}$ soil and $\mathrm{Cd}$ as a nitric acid salt of $\mathrm{Cd}$ (NO3) $2 \cdot 4 \mathrm{H} 2 \mathrm{O}$ in concentrations of 10 and $50 \mathrm{mg} / \mathrm{kg}$ soil.

The soil was packed into polyethylene containers of 5 liters and incubated at room temperature for 14 days. Before sowing the soil was moistened with distilled water to $60 \%$ of the PV and seeds were sown in the amount of 25 pieces per vessel.

In all variants of the experiment, the seeds were pre-treated with the fungicide Baytan wagon, SP at the rate of application rate of $2 \mathrm{~kg} / \mathrm{t}$ [4].

Plants were grown at a temperature of $18-20^{\circ} \mathrm{C}$ in conditions of constant soil moisture $(60 \% \mathrm{PV})$, which was controlled by daily weighing of the vessels. The placement of the vegetation vessels was changed daily according to a certain scheme, in order to ensure a more even illumination of the plants. Plants were harvested 21 days after sowing.

The development of the plants was monitored daily, the height of the plants was measured, the area of the leaf surface $\mathrm{s}(\mathrm{cm} 2)$ was calculated using the measured length and width of each sheet when it was fully formed. The raw mw and the absolutely dry md (after drying the plant material at $105{ }^{\circ} \mathrm{C}$ for 6 hours) were determined the mass of the plants.

The Cd content in the soil extracts and biomass of 7-21 diurnal plants (after wet ashing of the ground plant material with a mixture of $\mathrm{HNO} 3$ and $\mathrm{HClO} 4$ in a ratio of 3: 1) was determined by atomic absorption in a flame version on a Varian SpectrAA 250+ instrument.

Statistical processing of data was carried out using an application package in Microsoft Excel 2003.

\section{RESULTS AND DISCUSSION}

The addition of cadmium salt to the germination solution (roll method) at doses of 10 and $50 \mathrm{mg} / 1$ did not lead to significant changes in the germination index of the seeds. The magnitude of the growth force of the seeds also did not change and amounted to $96.7-98.7 \%$. At the same time, the development of the main embryonic barley root on the 7th day of development under the action of cadmium significantly ( $p<0.05$ compared to the control) slowed its growth by $11-12 \%$ irrespective of the cadmium dose in the solution (10 and $50 \mathrm{mg} / \mathrm{l}$ ). Against the background of the lag in the development of the spine, the length of the sprout did not practically change, and in the variant with the addition of cadmium salt at the maximum dosage $(50 \mathrm{mg} / \mathrm{l})$ even tended to increase.

The presence of cadmium ions inhibited the development of diseases of 7 diurnal barley shoots (Table 1). There was a significant decrease in the development of helminthosporiosis (by 17.7\% the extent of the lesion decreased and by $9.1 \%$ the prevalence of the disease on barley seedlings decreased, $\mathrm{p}$ $<0.05$ ), although fusarium rot was developing almost as well as in control, however, the degree of their development Was insignificant and amounted to - 0,7 - 3,4\%.

Table1. Disease of 7-days-old barley seedlings

\begin{tabular}{|l|c|c|c|c|}
\hline \multirow{2}{*}{ Variant } & \multicolumn{2}{|c|}{ Helminthosporium sativum } & \multicolumn{2}{|c|}{ Fusarium sp. } \\
\cline { 2 - 5 } & $\begin{array}{c}\text { Degree of } \\
\text { defeat, } \%\end{array}$ & Prevalence, & $\begin{array}{c}\text { Degree of } \\
\text { defeat, } \%\end{array}$ & Prevalence, $\%$ \\
\hline Control & 34,4 & 92,0 & 1,3 & 4,3 \\
\hline $\mathrm{Cd}_{50}$ & $28,3^{*}$ & $83,7 *$ & 3,4 & 9,0 \\
\hline $\mathrm{Cd}_{50}+\mathrm{Z}$ & $29,6^{*}$ & $94,0 \cdot$ & 0,7 & 2,3 \\
\hline
\end{tabular}

Here and below: * the difference with the control is significant at $p \leq 0.95 ;-$ - the differences are significant at $p \leq 0.95$ compared to the same variant, but without seed treatment with Zircon 
Two weeks after the germination of the tendency to change the indices of development of seedlings during the incubation of seeds in the solution, the cadmium salts were preserved (Figure 1). The growth of the rootlet was practically unchanged from the data of 7 diurnal shoots, while the length of the sprout was increased by $16.9 \%$ at a Cd concentration of $10 \mathrm{mg} / 1$ and by $5.6 \%$ at a concentration of $50 \mathrm{mg} / 1$. Regardless of the dose of cadmium deposition, the suppression of root development in 7 and 14 day old seedlings was almost the same.

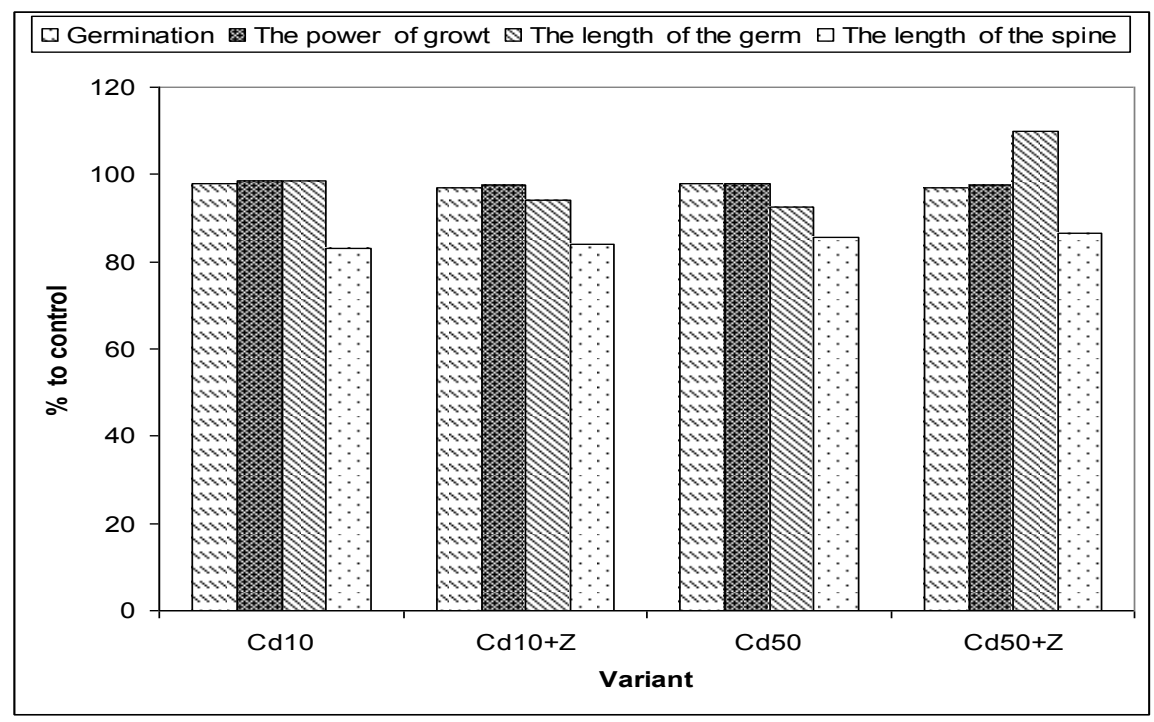

Fig1. Effect of Zircon Plant Growth Regulator on the development of 14-day barley seedlings

The use of the zircon regulator for the treatment of barley seeds had a stimulating effect on the development of the sprout with a high dose of cadmium content in the seed germination solution. This manifested itself in a significant increase in its length in the variant $\mathrm{Cd}$ on the 7th and 14th day of the development of barley seedlings (Fig. 1). Depression of the development of the root caused by the action of cadmium ions, the use of Zircon did not remove.

An important indicator of the development of plants at all stages of their growth is the value of biomass. The use of PPP can largely determine the rate of increase in the mass of dry matter, but the magnitude of the effect depends on the type and the effective concentration of the preparation, the method of its application, and the provision of nutrients to the soil. When cadmium barley seeds were added to the solution for germination at doses of 10 and $50 \mathrm{mg} / 1$, a significant decrease in the dry biomass of 7 diurnal seedlings was observed in comparison with the control. Processing of seeds with zircon made it possible to reduce the negative effect of cadmium on the accumulation of seedlings biomass. The greatest effect of Zircon was manifested in the version where the dose of cadmium was $10 \mathrm{mg} / 1$ (the increase in the dry mass of plants was $15-16 \%$ compared to those in variants without seed treatment with the preparation).

The introduction of cadmium into the soil for the cultivation of barley varieties Elf (vegetation experience) adversely affected the development of plants. The cadmium content in the soil, which is much higher than the MAC for sod-podzolic medium loam soil, led to a significant decrease in plant height of 21 daily barley plants and leaf area (by 17\% relative to control), regardless of the experiment. Presowing treatment of seeds with Zircon allowed to reduce the phytotoxic effect of cadmium only in terms of the accumulation of dry mass of plants (Table 2).

Table2. Indices of development of barley plants

\begin{tabular}{|c|c|c|c|c|c|c|c|c|c|}
\hline \multirow[t]{4}{*}{ Variant } & 10 days & \multicolumn{8}{|c|}{21 days } \\
\hline & \multirow{3}{*}{$\underset{2}{\mathrm{ASS}, \mathrm{cm}}$} & \multirow{3}{*}{$\begin{array}{l}\text { Height of } \\
\text { plants, } \\
\mathrm{cm}\end{array}$} & \multicolumn{5}{|c|}{ Leaf area, $\mathrm{cm}^{2}$} & \multicolumn{2}{|c|}{ Weight of sprouts, $g$} \\
\hline & & & \multirow[t]{2}{*}{1} & \multirow[t]{2}{*}{2} & \multirow[t]{2}{*}{3} & \multirow[t]{2}{*}{4} & \multirow[t]{2}{*}{ total } & & \\
\hline & & & & & & & & damp & dry \\
\hline Control & 4.7 & 31.6 & 4.5 & 6.1 & 6.9 & 4.8 & 22.3 & 0.50 & 0,063 \\
\hline $\mathrm{Z}$ & 5.0 & 31.3 & 5.2 & 6.2 & 7.0 & 4.7 & 23.1 & 0.53 & 0,061 \\
\hline $\mathrm{Cd}_{50}$ & $4.0 * \bullet$ & $29.9 *$ & 4.6 & 5.5 & 6.2 & 2.5 & $18.9 *$ & $0.40 *$ & $0,050 *$ \\
\hline $\mathrm{Cd}_{50}+\mathrm{Z}$ & 4.7 & $29.3^{*}$ & 4.5 & 5.3 & 5.8 & 3.4 & $19.0^{*}$ & $0.41^{*}$ & $0,058 \bullet$ \\
\hline
\end{tabular}


The Cd content in plant samples of barley seedlings, in the growth medium of which no additional salts of this metal (control) were added, was $3.5-4.0 \mathrm{mg} / \mathrm{kg}$. At the content of cadmium in the solution for germination of barley seeds in doses of 10 and $50 \mathrm{mg} / 1$, the accumulation of metal in plants was 50.9 and $134.6 \mathrm{mg} / \mathrm{kg}$, respectively. An increase in the dose of metal in the solution for seed germination by a factor of 5 led to an increase in the cadmium content in dry biomass of 7 diurnal barley seedlings only by a factor of 2.6.

Seed treatment with zircon resulted in a reduction of cadmium content by $43.8 \%$ at a cadmium concentration of $10 \mathrm{mg} / 1$ and by $34.7 \%$ at a concentration of $50 \mathrm{mg} / 1$ compared to a similar option without the use of PPP (the differences are significant compared to the control at $\mathrm{p}<0.05$ ) (Figure 2.).

Two weeks after the germination of seeds, trends in the accumulation of cadmium persisted. At the same time, differences in the accumulation of the element with its different content for the more mature plants were less significant and amounted to 1,29 times. This is primarily due to the rate of accumulation of plant biomass (and also, the accumulation of dry matter) during this period and development.

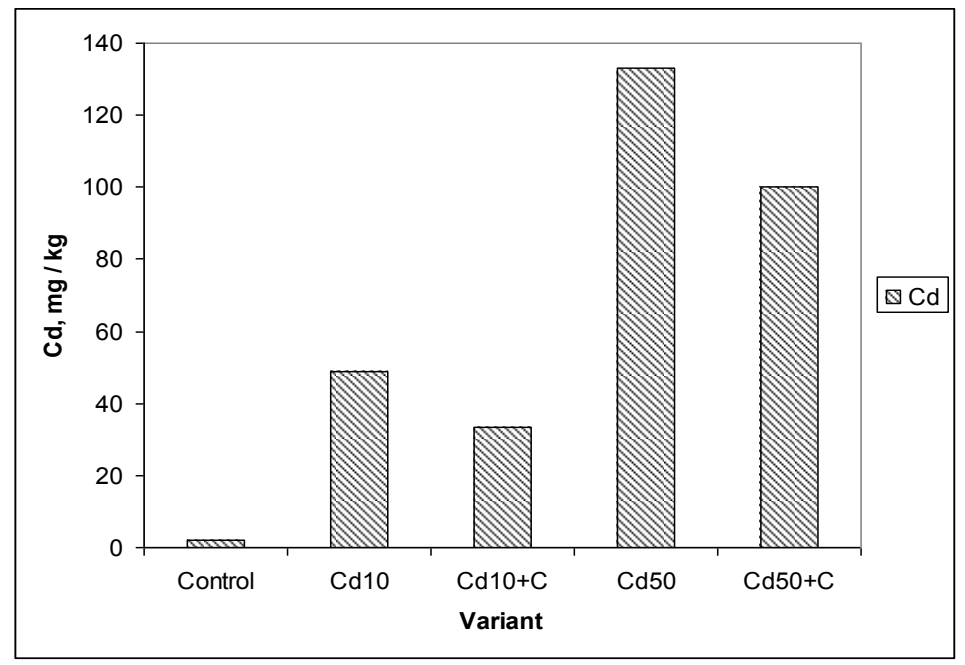

Figure2. $\mathrm{Cd}$ content $(\mathrm{mg} / \mathrm{kg})$ in the biomass of 7-day barley seedlings

Irradiation of seeds in doses of $1 \mathrm{~Gy}$ and $10 \mathrm{~Gy}$ did not cause significant changes in the accumulation of cadmium during its growth without the addition of cadmium to the germination solution.

When growing barley plants in soil with an increased content of $\mathrm{Cd}$, an increase in its content in the soil by 83 times (compared with the background level) led to an increase in accumulation in plants by almost 53 times. This indicates the mechanisms regulating the entry of ions of heavy metals with their excessive content in the soil. Attention is drawn to the fact that when soil $\mathrm{Cd}(50 \mathrm{mg} / \mathrm{kg})$ was contaminated under the influence of Zirkon, the accumulation of metal in plants was reliably reduced $(\mathrm{p}<0.05)$. However, if for 7-14 day plants the coefficient of modification (the ratio of the element in the variant without and using Zircon) was greater than one (about 1.4), then in the case of growing plants in the soil for 3 weeks, he wore another The direction was 0.9 .

\section{Conclusions}

Thus, the obtained results indicate that the treatment of barley seeds of the Elf variety by the plant growth regulator Zircon, as a whole, helps to reduce the phytotoxic effect of cadmium with an increased content of this element in the solution for seed germination and in the soil. The use of Zircon leads to a decrease in the accumulation of cadmium in the biomass of barley plants at various stages of ontogeny.

\section{REFERENCES}

[1] Malevannaya N.N. Zircon is a new stimulator of plant growth and development. In: Regulators of plant growth and development in biotechnology. M., 2001. With 111.

[2] Ulyanenko LN, Arysheva SP, Filipas AS, Kruglov SV, Malevannaya NN, Pimenov EP Productivity, morphometric attributes of spring wheat plants and accumulation of cadmium in the crop under the influence of the Zircon growth regulator // Agricultural Biology. 2005. A series of plant biology. №5. C.75-80. 
[3] Seeds of agricultural crops. A) Methods for determining quality. Part 2. State standards of the USSR. GOST 12038 - 84. M: 1991. With. 44 - 101.

[4] Handbook of pesticides and agrochemicals allowed for use in the Russian Federation. Moscow: Agrorus, 2003. 410 p.

[5] Seeds of agricultural crops. B) Methods for determining quality. Part 2. State standards of the USSR. GOST 12044 - 81. Methods for determining infection with diseases. M: 1991. P. 250 251.

[6] Zhurbitsky Z.I. Theory and practice of the vegetative method. - Moscow: Nauka, 1968. - 206 p.

[7] Workshop on Agrochemistry: Proc. Allowance. - 2 nd ed., Pererab. And additional. Ed. Academician of the Russian Academy of Agricultural Sciences. Mineev. - Moscow: Publishing House of Moscow State University, 2001.-689 p.

[8] Workshop on agrochemistry / BA. Yagodin, I.P. Deryugin, Yu.P. Zhukov et al; Ed. BA Yagodin. - Moscow: Agropromizdat, 1987. 512 p. 